\title{
Sources of variability in consonant perception and their auditory correlates
}

\author{
Zaar, Johannes; Dau, Torsten
}

Publication date:

2015

Document Version

Publisher's PDF, also known as Version of record

Link back to DTU Orbit

Citation (APA):

Zaar, J., \& Dau, T. (2015). Sources of variability in consonant perception and their auditory correlates. Poster session presented at 169th Meeting of the Acoustical Society of America, Pittsburgh, Pennsylvania, United States.

\section{General rights}

Copyright and moral rights for the publications made accessible in the public portal are retained by the authors and/or other copyright owners and it is a condition of accessing publications that users recognise and abide by the legal requirements associated with these rights.

- Users may download and print one copy of any publication from the public portal for the purpose of private study or research.

- You may not further distribute the material or use it for any profit-making activity or commercial gain

- You may freely distribute the URL identifying the publication in the public portal

If you believe that this document breaches copyright please contact us providing details, and we will remove access to the work immediately and investigate your claim 
Johannes Zaar and Torsten Dau

Hearing Systems Group, Department of Electrical Engineering, Technical University of Denmark, DK-2800, Kgs. Lyngby, Denmark

\section{BACKGROUND AND OBJECTIVE}

Responses obtained in consonant perception experiments typically show a large variability across stimuli of the same phonetic identity (Phatak at al., 2008; Sing \& Allen, 2012; Toscano \& Allen, 2014)

The present study investigated the influence of different potential sources of this response variability. It was distinguished between source-induced variability, referring to perceptual differences caused by acoustical differences in the speech tokens and/or the masking noise tokens, and receiverrelated variability, referring to perceptual differences caused related variably, refening to perceptual diserences caused by whin- and across-listener uncertainty. It can be thes measuabe effec. This holds even for slight time-shifs in the steady-state masking noise waveform. Furthermore, responses obtained wh hidentical stimuli differed substantially across different normal-hearing listeners, while individua listeners were able to reproduce their responses fairly reliably. To determine how well the source-induced variability is reflected in different auditory-inspired intern representa were comp stimuli Several variants of an energy-based IR and modulation-based IR were considered. The resuls sugest that a normalized modulation the best match to the perceptual data.

\section{EXPERIMENTS}

- 15 CVs: /bi, di, fi, gi, hi, ji, ki, li, mi, ni, pi, si, fi, ti, vi/ - Presented in white noise @ 12, 6, 0, -6, -12, and -15 dB SNR - 8 young normal-hearing native Danish listeners

Experiment 1: Speech variability

- 3 speech tokens of each CV spoken by a male talker (A)

- 3 speech tokens of each CV spoken by a female talker (B)

- Each token mixed with different frozen noise waveforms at

$12,6,0,-6,-12$, and $-15 \mathrm{~dB}$ SNR

- Three observations per stimulus and listener

Experiment 2: Noise variability

- 1 speech token of each CV spoken by a male talker

- Each mixed with

$>$ Frozen noise " $\mathrm{A}$ "

Frozen noise "B" (noise "A" shifted by $100 \mathrm{~ms}$ )

Random noise

- At 12, 6, 0, -6, - 12 , and - $15 \mathrm{~dB}$ SNR

- Different frozen noises used for the different tokens

- Re-test with a subset of 4 listeners

- Five observations per stimulus and listener

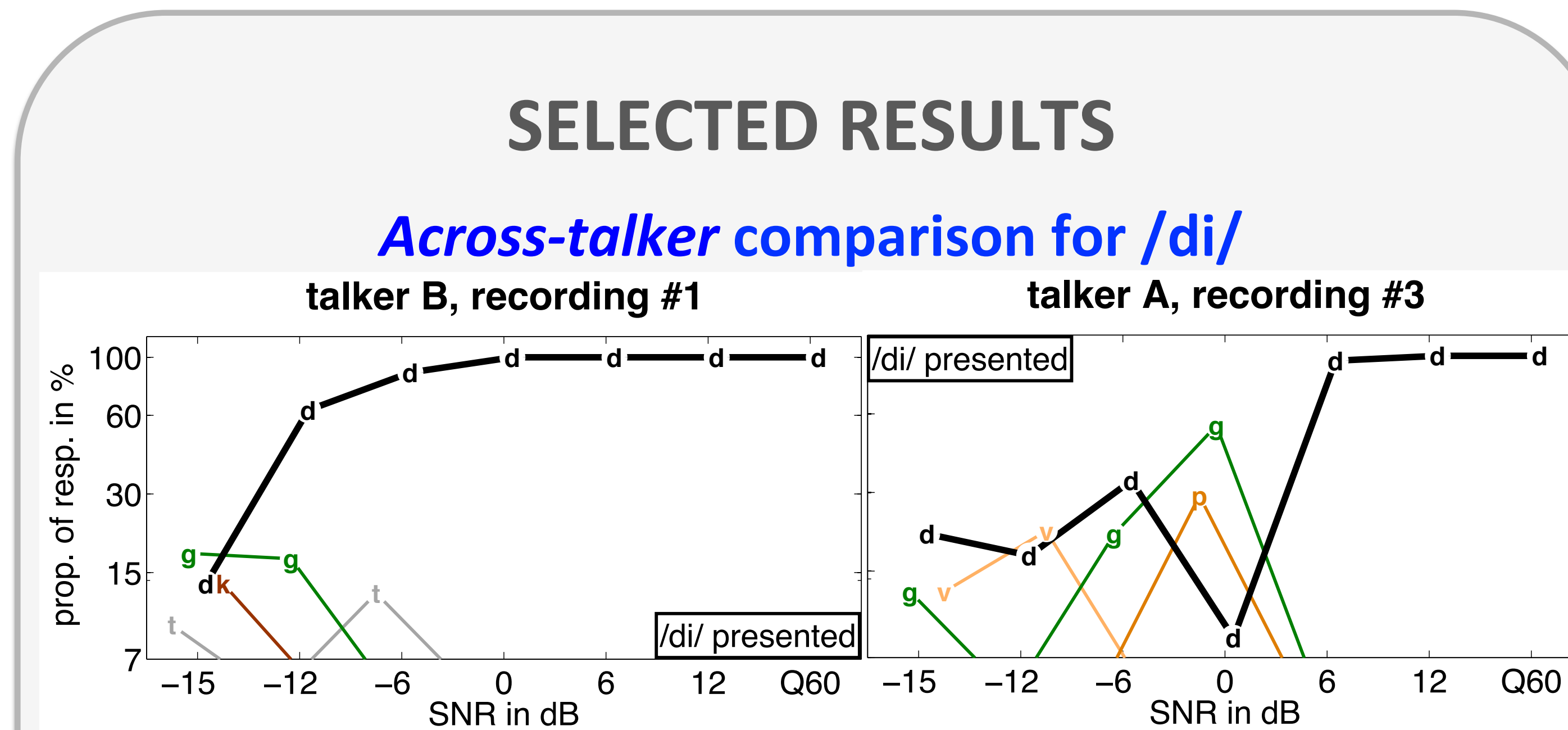

$\Rightarrow$ Large influence of across-talker articulatory differences

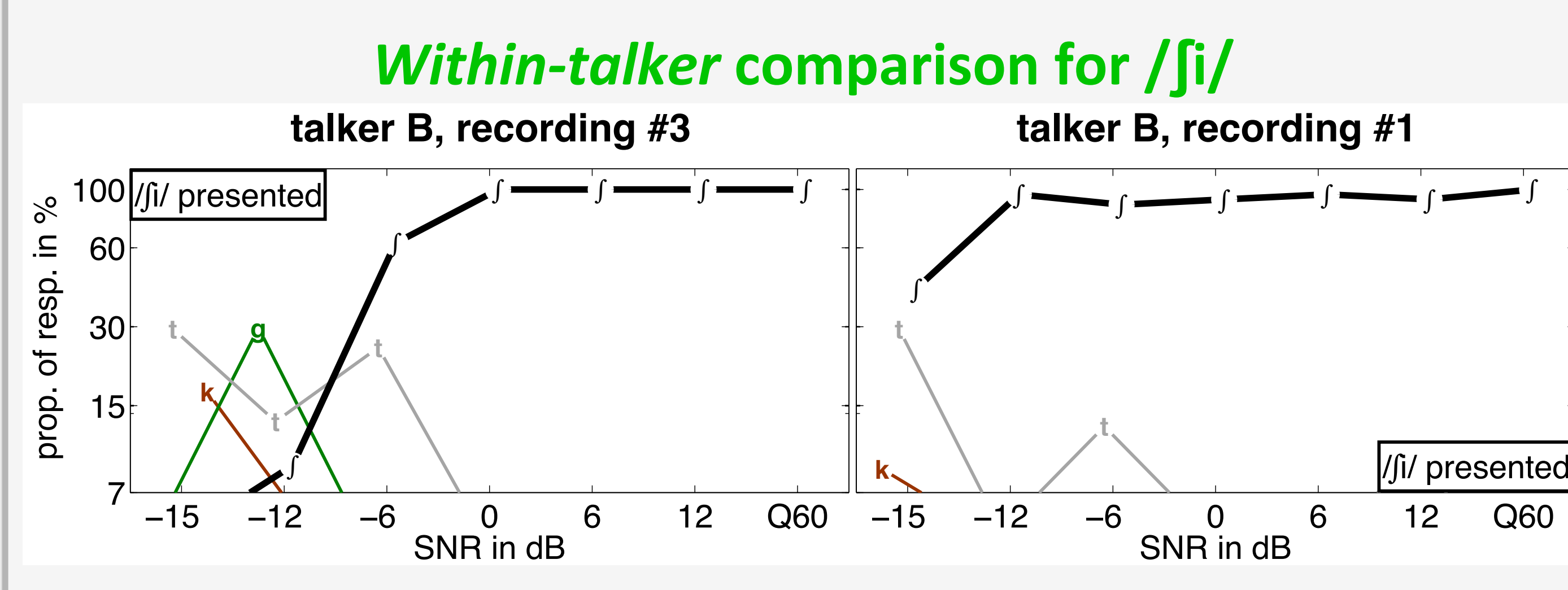

$\Rightarrow$ Large influence of within-talker articulatory differences

Across noise-token comparison for /gi// frozen noise A frozen noise $\mathrm{B}$

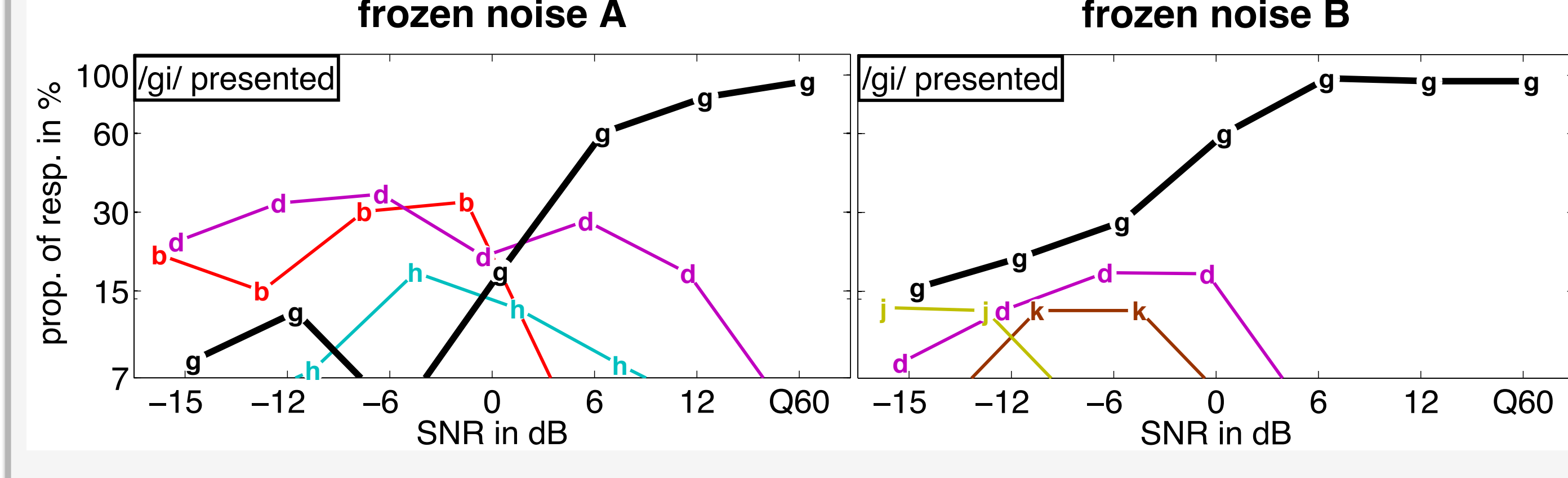

$\Rightarrow$ Considerable influence even of a $100-\mathrm{ms}$ time shift in the masking noise waveform

Across-listener comparison for / $\mathrm{ni} /$ frozen noise B, first run, listener 3

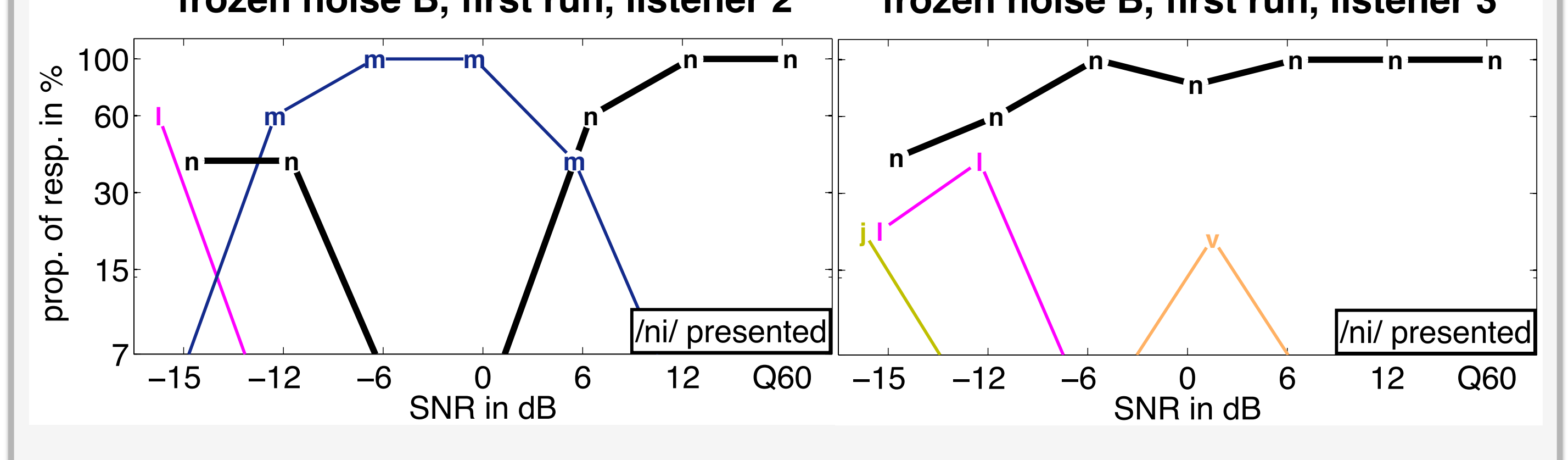

$\Rightarrow$ Large influence of across-listener differences for identical stimuli

Re-test data for / $\mathrm{ni} /$, same listeners

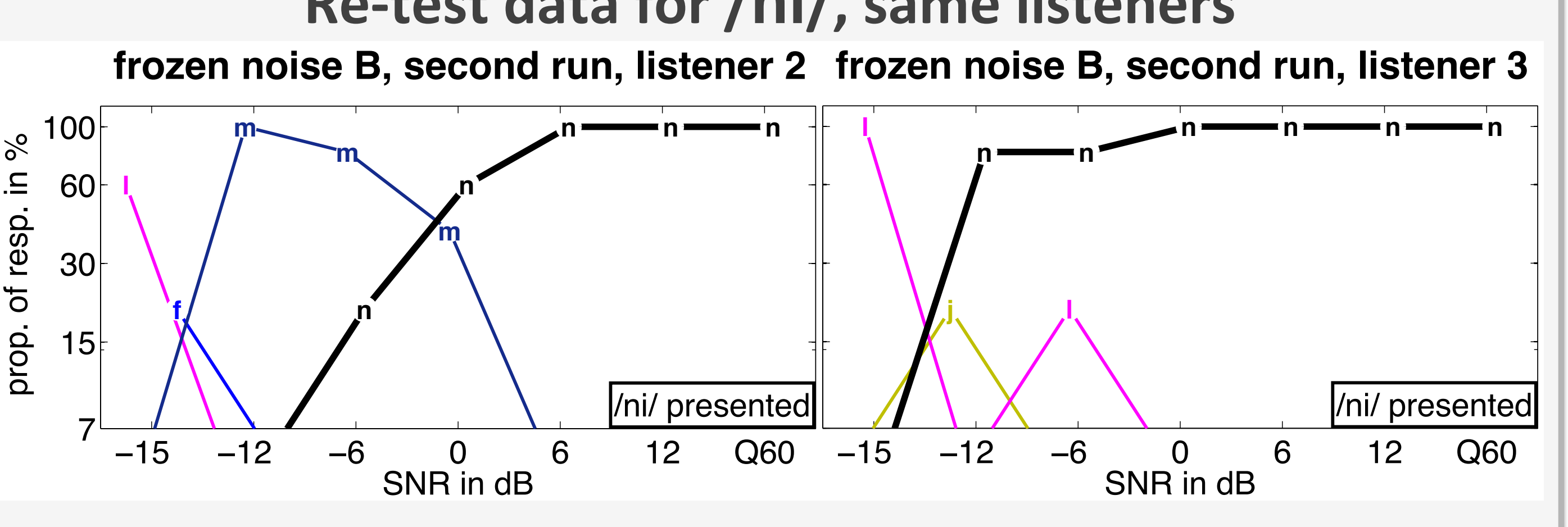

$\Rightarrow$ Good reproducibility for individual listeners in test and retest (for identical stimuli)

\section{ANALYSIS}

Perceptual distance definition

To quantify the perceptual effect of the considered factors, a measure of the perceptual distance between responses was defined. The responses of a given listener, obtained with a given stimulus, were treated as vectors $r=\left[p_{b}, p_{d}, \ldots, p_{v}\right]$, where $p_{x}$ denotes the proportion of response " $x$ ". The perceptual distance between two such response vectors $r_{1}$ and $r_{2}$ was defined as the normalized angular distance between them:

$$
D\left(r_{1}, r_{2}\right)=\arccos \left(\frac{\left\langle r_{1}, r_{2}\right\rangle}{\left\|r_{1}\right\| \cdot\left\|r_{2}\right\|}\right) \cdot \frac{100 \%}{\pi / 2}
$$

Perceptual Distance calculation across six factors

Reference:

across CVs

Source-induced: across talkers, within talkers,

across noise tokens

Receiver-related: across listeners, within listeners

Apart from the across-CV factor, only responses obtained with stimuli of the same phonetic identity were compared. For each considered factor, the perceptual distance was calculated across all pairwise comparisons of response vectors representative of that factor. The calculation was performed for each SNR condition separately and the individual distance values were averaged across the considered response pairs and across listeners.

QUANTIFICATION OF FACTORS

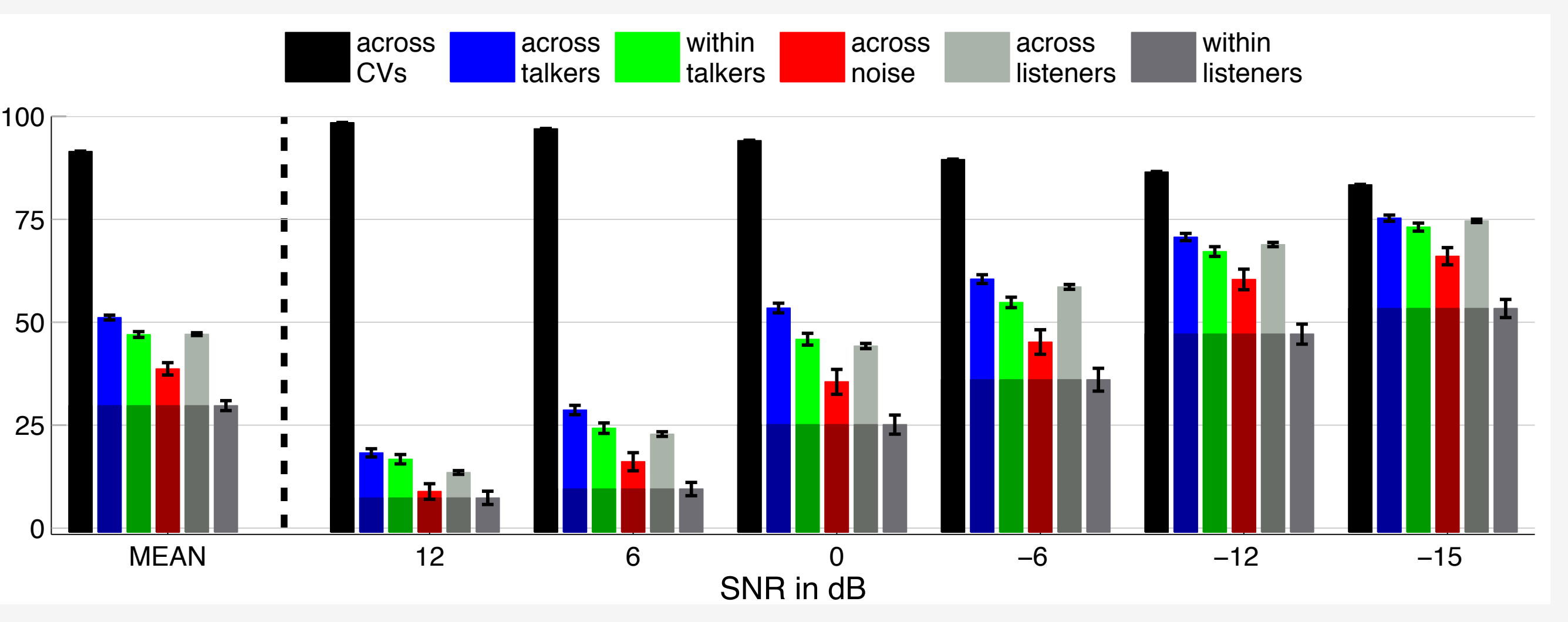

$\Rightarrow \mathrm{CV}$-in-noise perception critically depends on

$>$ Speech-token specific effects

Masking-noise-token specific effects

$\Rightarrow$ Perceptual distances across listeners much more pronounced than within listeners

$\Rightarrow$ Within-listener perceptual distance (internal noise) inversely related to SNR
MODELING

Energy-based representation

$$
s(t) \rightarrow
$$

Configurations: LP @ 2, 4, 8, 16, 32, 64, 128, 256 Hz

Modulation-based representation

$$
s(t) \rightarrow \underset{\text { mod }}{:}\left(t, f_{c}, f_{m}\right)
$$

Configurations: $f_{m}=2 \mathrm{~Hz}, f_{m}=[2,4] \mathrm{Hz}, \ldots, f_{m}=[2,4,8,16,32,64,128,256] \mathrm{Hz}$ AC-coupled modulation-based representation

$$
P_{\text {mod }}^{a c}=\frac{P_{\text {mod }}}{D C_{\text {subband }}}
$$

Modeled distance versus perceptual distance The modeled distance was calculated between the mode epresentations of the stimuli using a dynamic time warpin algorithm. Only the source-induced factors were considered (across CVs, across talkers, within talkers, across noise tokens), using the same pairwise comparisons of stimuli that had been compared in the perceptual distance calculation.

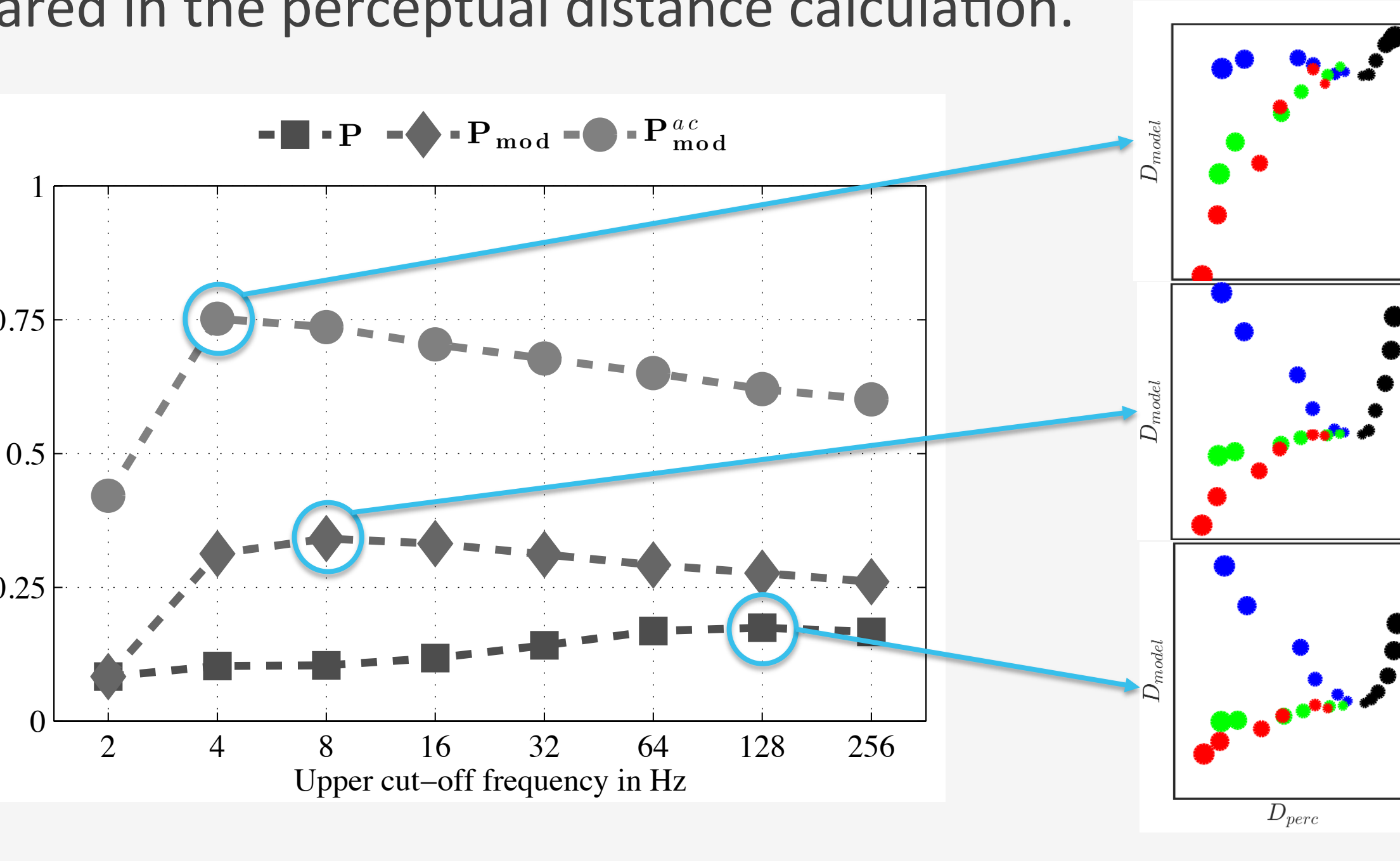

$\Rightarrow$ AC-coupled modulation representation closest to the perceptual data (least overestimation of across-talker distances)

ACKNOWLEDGEMENTS

This research was supported by the European Community FP7 Marie Curie Initial Training Network INSPIRE.

\section{REFERENCES}

Phatak, S.A., Lovitt, A., Allen, J.B. (2008): "Cons
Acoust. Soc. Am. 124 (2): 1220-1233.

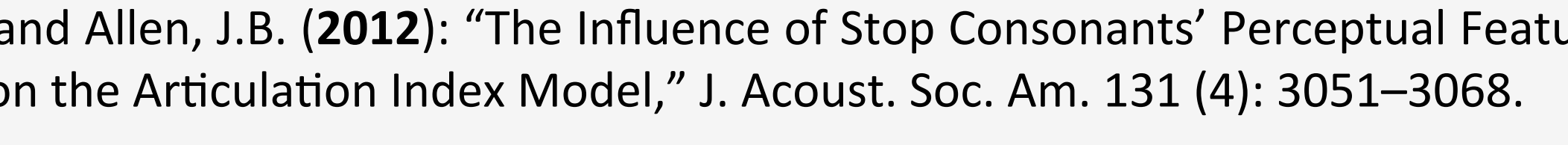
J.C. and Allen, J.B. (2014): "Across- and Within-Consonant Errors for Isolated
Syllables in Noise," Juurnal of Speech, Language, and Hearing Research 57:
$22293-2307$. 